Buletin Ilmiah Math. Stat. dan Terapannya (Bimaster)

Volume 09, No. 2 (tahun), hal $267-274$.

\title{
ANALISIS RISIKO PORTOFOLIO LQ45 MENGGUNAKAN PENDEKATAN VALUE AT RISK BLOCK MAXIMA- GENERALIZED EXTREME VALUE
}

\author{
Nanda Ayuni, Setyo Wira Rizki, Hendra Perdana
}

\begin{abstract}
INTISARI
Setiap bentuk investasi memiliki risiko yang dapat menyebabkan kerugian bagi investor. Semakin tinggi hasil yang diharapkan dari investasi tersebut, maka semakin tinggi juga tingkat risikonya. Dengan demikian, investor perlu mengetahui besar risiko yang akan dihadapinya, sehingga dapat melakukan tindakan pencegahan agar bisa mengantisipasi risiko tersebut. Metode yang dapat digunakan untuk mengukur risiko adalah value at risk (VaR). Extreme value theory (EVT) merupakan metode yang digunakan untuk mengukur risiko pada data runtun waktu yang memiliki distribusi ekor gemuk. Distribusi ekor gemuk memiliki kecenderungan lebih besar terjadinya kejadian ekstrem dibandingkan dengan distribusi normal. Umumnya, hal ini ditandai oleh nilai kurtosis yang positif. Salah satu metode EVT adalah block maxima yang mengikuti distribusi GEV (generalized extreme value). Perhitungan VaR yang akurat pada data runtun waktu finansial dapat menggunakan VaR dengan metode block maximaGEV. Penelitian ini menggunakan data harga saham penutupan harian pada indeks LQ45 periode 1 Januari sampai 31 Desember 2018. Saham yang digunakan untuk pembentukan portofolio ada lima yaitu PTBA, ANTM, PGAS, BBCA, dan ICBP, yang mana saham-saham tersebut dipilih berdasarkan nilai mean return tertinggi. Berdasarkan hasil analisis, diperoleh nilai VaR dengan metode block maximaGEV dengan tingkat kesalahan 5\% adalah sebesar 2,555\% dari total nilai investasinya. Misalnya, jika investor berinvestasi sebesar Rp100.000.000,00,- maka investor tersebut mempunyai risiko sebesar Rp2.555.000,00.
\end{abstract}

Kata Kunci : investasi, VaR, extreme value theory, heavy tail

\section{PENDAHULUAN}

Pasar modal memiliki peranan penting sebagai salah satu tempat investasi keuangan dalam dunia perekonomian, sehingga pasar modal dapat digunakan sebagai media investasi[1]. Investasi adalah penanaman modal untuk satu atau lebih aktiva yang dimiliki dan biasanya berjangka waktu lama dengan harapan mendapatkan keuntungan di masa yang akan datang. Setiap bentuk investasi memiliki risiko yang akan menyebabkan kerugian bagi investor. Semakin tinggi hasil yang diharapkan dari investasi tersebut, semakin tinggi pula tingkat risikonya. Sebelum melakukan investasi, investor sangat penting untuk memahami risiko. Dengan mengetahui risiko yang akan dihadapi, investor dapat melakukan tindakan pencegahan agar risiko tersebut tidak dihadapi investor atau setidaknya dapat mengantisipasi risiko. Salah satu elemen yang sangat penting dalam pengelolaan risiko adalah ukuran risiko[2]. Metode atau alat yang dapat digunakan untuk mengukur risiko adalah value at risk (VaR). VaR dapat diartikan sebagai ukuran kerugian terburuk atau maksimum yang diperkirakan akan terjadi pada kondisi pasar yang normal dengan tingkat kepercayaan tertentu[3].

Pada data runtun waktu finansial diduga memiliki distribusi ekor yang gemuk (heavy tail) yaitu ekor distribusi yang turun secara lambat jika dibandingkan dengan distribusi normal, sehingga hal ini menyebabkan peluang terjadinya nilai ekstrem. Extreme value theory (EVT) merupakan metode yang digunakan untuk mengukur risiko pada data runtun waktu finansial yang memiliki ekor distribusi gemuk. Terdapat dua metode pada pendekatan VaR dengan adanya EVT, yaitu block-maxima dan peaks over threshold[4]. Metode block maxima merupakan metode yang mengidentifikasikan nilai ekstrem berdasarkan nilai maksimum dari data observasi yang dikelompokkan berdasarkan periode tertentu. Metode ini mengikuti distribusi generalized extreme value (GEV)[5]. 
Tujuan dari penelitian ini adalah menganalisis risiko portofolio LQ45 menggunakan VaR dengan pendekatan metode block maxima-GEV. Studi kasus pada penelitian ini menggunakan data sekunder yaitu data harga saham penutupan LQ45. Proses memilih saham yang dianalisis yaitu dipilih saham yang selalu terdaftar atau konsisten masuk ke dalam LQ45. Kemudian dihitung return, lalu mean return dari masing-masing saham yang konsisten masuk ke dalam indeks LQ45. Selanjutnya dipilih lima saham yang memiliki nilai mean return positif tertinggi. Proses menghitung nilai return portofolio yaitu dengan menentukan bobot $w_{1}, w_{2}, w_{3}, w_{4}$ dan $w_{5}$ dari kelima saham yang digunakan. Nilai return portofolio dihitung berdasarkan proporsi nilai mean return saham untuk masing-masing kelima saham yang digunakan untuk portofolio. Setelah itu, dilakukan uji apakah data return portofolio yang diperoleh memenuhi kondisi adanya GEV. Hal ini dilakukan dengan uji kesesuaian distribusi menggunakan uji Kolmogorov-Smirnov. Jika data return portofolio memenuhi kondisi adanya GEV maka dilanjutkan dengan estimasi nilai parameter GEV yaitu parameter lokasi $(\beta)$, parameter skala $(\alpha)$, dan parameter bentuk $(\xi)$. Selanjutnya, dihitung nilai VaR-GEV dengan pemilihan jumlah blok yaitu $n=52$. Sehingga diperoleh risiko portofolio LQ45.

\section{RETURN SAHAM}

Return merupakan salah satu faktor yang memotivasi investor dan juga merupakan imbalan keberanian investor menanggung risiko atas investasi yang dilakukan[6]. Pada penelitian ini digunakan continuously compounding return (log return), yaitu[7]:

$$
r_{t}=\ln \frac{S_{t}}{S_{t-1}}
$$

dengan $r_{t}$ adalah return waktu ke- $t ; S_{t}$ adalah harga aset pada waktu $t$; dan $S_{t-1}$ adalah harga aset pada waktu $t-1$.

\section{PORTOFOLIO}

Portofolio merupakan suatu kumpulan atau kelompok atau penggabungan atau kombinasi yang membentuk suatu unit, dimana isinya adalah aktiva atau sekuiritas keuangan seperti saham, obligasi, dan setara kas. Proses menghitung return portofolio digunakan, yaitu[7]:

$$
r_{t p}=\sum_{i=1}^{N} w_{i} r_{i t}
$$

dengan $r_{t p}$ adalah return portofolio pada waktu ke- $t ; w_{i}$ merupakan bobot aset ke- $i ; r_{i t}$ adalah return aset ke- $i$ pada waktu ke- $t$; dan $N$ merupakan banyaknya aset dalam portofolio.

\section{UJI KESESUAIAN DISTRIBUSI}

Uji kesesuaian distribusi bertujuan untuk menunjukkan adanya kesesuaian distibusi teoritis. Satu diantara teknik yang digunakan untuk uji kesesuaian distribusi adalah uji Kolmogorov-Smirnov (K-S). Konsep Kolmogorov-Smirnov adalah membandingkan distribusi teoritik dan distribusi empirik (observasi) berdasarkan frekuensi kumulatif[8].

Misalkan $X_{1}, X_{2}, \ldots, X_{n}$ adalah sampel random berukuran $n$ dari suatu populasi dengan fungsi distribusi $F(x)$. Andaikan $F_{0}(x)$ adalah suatu fungsi distribusi tertentu dan akan diuji:

$$
\begin{array}{ll}
H_{0}: F(x)=F_{0}(x) \text { untuk semua } x & \text { (data berdistribusi tertentu) } \\
H_{1}: F(x) \neq F_{0}(x) \text { untuk semua } x & \text { (data tidak berdistribusi tertentu) }
\end{array}
$$

Uji Kolmogorov-Smirnov menggunakan statistik uji:

$$
D=\max \left|F_{0}(x)-S_{N}(x)\right|
$$


$F_{0}(x)$ adalah fungsi distribusi frekuensi kumulatif teoritis dan $S_{N}(x)$ adalah distribusi frekuensi kumulatif yang diamati dari suatu sampel random dengan $n$ observasi. Kesimpulan yang diambil adalah menolak $H_{0}$ jika nilai $D>D_{\operatorname{tabel}(n, \alpha)}$ atau tolak $H_{0}$ jika $p$-value < tingkat kesalahan (alpha).

\section{EXTREME VALUE THEORY (EVT)}

Extreme Value Theory (EVT) merupakan teori yang berfokus pada perilaku ekor (tail) dari suatu distribusi. EVT biasanya digunakan untuk memodelkan kondisi-kondisi yang bersifat ekstrem, seperti kerugian yang jarang terjadi tetapi memiliki dampak yang sangat besar[9]. Terdapat dua macam metode dalam EVT, yaitu block maxima dan peaks over threshold (POT). Metode block maxima merupakan metode yang cara pengembilan suatu data dengan cara mengambil nilai maksimum dalam suatu periode, dengan pengamatan yang nilainya maksimum dianggap sebagai nilai ekstrem. Metode block maxima mengikuti distribusi generalized extreme value (GEV). Metode POT merupakan metode dengan melihat nilai-nilai yang melampaui satu nilai threshold (ambang) tertentu dianggap memiliki nilai ekstrem dan mengikuti generalized pareto distribution (GPD)[2].

\section{METODE BLOCK MAXIMA-GEV}

Metode block maxima merupakan metode yang dikembangkan oleh Fisher dan Tippet (1928) serta Gnedenko (1943)[4]. Metode block maxima mengikuti distribusi generalized extreme value (GEV). GEV memiliki cumulative distribution function (CDF), yaitu[9]:

$$
H_{\xi}(x)=\left\{\begin{array}{l}
\exp \left[-(1+\xi x)^{-\frac{1}{\xi}}\right] ; \xi \neq 0 \\
\exp [-\exp (-x)] ; \xi=0
\end{array}\right.
$$

dengan $\xi$ adalah parameter bentuk (shape) dan $x$ memenuhi $1+\xi x>0$.

Distribusi GEV adalah keluarga dari distribusi kontinu yang dibangun dalam EVT untuk mengkombinasikan distribusi Gumbel, Frechet, dan Weibull yang dikenal sebagai distribusi extreme value tipe I, II, dan III. Distribusi Gumbel, Frechet, dan Weibull memiliki fungsi distribusi kumulatif atau cumulative distribution function (CDF) sebagai berikut[10]:

1. Distribusi Gumbel (distribusi GEV tipe I) untuk $\xi=0$, memiliki CDF, yaitu:

$$
\Lambda(x)=\exp [-\exp (-x)] ;-\infty<x<\infty
$$

2. Distribusi Frechet (distribusi GEV tipe II) untuk $\xi>0$, memiliki CDF, yaitu:

$$
\Phi_{\xi}(x)=\left\{\begin{array}{l}
\exp \left[-(1+\xi x)^{-\frac{1}{\xi}}\right] ; x>-\frac{1}{\xi} \\
0 ; \text { lainnya }
\end{array}\right.
$$

3. Distribusi Weibull (distribusi GEV tipe III) untuk $\xi<0$, memiliki CDF, yaitu:

$$
\psi_{\xi}(x)=\left\{\begin{array}{l}
\exp \left[-(1+\xi x)^{-\frac{1}{\xi}}\right] ; x<-\frac{1}{\xi} \\
1 ; \text { lainnya }
\end{array}\right.
$$

Jika CDF distribusi GEV yang disajikan pada Persamaan (4) distandarkan, maka rumusan yang melibatkan parameter bentuk $\xi$, parameter lokasi $\beta$, dan parameter skala $\alpha$ ditulis dalam bentuk:

$$
H_{\xi}(x)=H_{\xi}\left(\frac{x-\beta}{\alpha}\right),-\infty<\beta<\infty, \alpha>0
$$

Persamaan (4) yang telah distandarkan dapat dituliskan, yaitu[1]: 


$$
H_{\xi, \beta, \alpha}(x)=\left\{\begin{array}{l}
\exp \left\{-\left(1+\xi\left(\frac{x-\beta}{\alpha}\right)\right)^{-\frac{1}{\xi}}\right\} ;-\infty<x<\infty ; 1+\xi\left(\frac{x-\beta}{\alpha}\right)>0 ; \xi \neq 0 \\
\exp \left\{-\exp \left(-\frac{x-\beta}{\alpha}\right)\right\} ;-\infty<x<\infty ; \xi=0
\end{array}\right.
$$

Fungsi kepadatan peluang atau probability density function (PDF) untuk distribusi GEV, yaitu [2]:

$$
f(x ; \beta, \alpha, \xi)=\left\{\begin{array}{l}
\frac{1}{\alpha}\left\{1+\xi\left(\frac{x-\beta}{\alpha}\right)\right\}^{-\frac{1}{\xi}-1} \exp \left\{-\left(1+\xi\left(\frac{x-\beta}{\alpha}\right)\right)^{-\frac{1}{\xi}}\right\} ; \xi \neq 0 \\
\frac{1}{\alpha} \exp \left\{-\frac{x-\beta}{\alpha}\right\} \exp \left\{-\exp \left(-\frac{x-\beta}{\alpha}\right)\right\} ; \xi=0
\end{array}\right.
$$

Parameter bentuk $\xi$ menentukan perilaku ekor (tail) dari distribusi. GEV dapat dibedakan dalam tiga tipe, yaitu tipe I (distribusi Gumbel) jika nilai $\xi=0$, tipe II (distribusi Frechet) jika nilai $\xi>0$, dan tipe III (distribusi Weibull) jika nilai $\xi<0$. Semakin besar nilai $\xi$, maka semakin gemuk juga ekor distribusinya (heavy tail). Dengan demikian, dari ketiga tipe distribusi GEV, yang memiliki ekor paling gemuk adalah distribusi Frechet [9].

Asumsikan bahwa sub-periode maksimum $\left\{l_{n, i}\right\}$ mengikuti distribusi extreme value sehingga PDF dari $x_{i}=l_{n, i}$ pada Persamaan (10) dapat ditetapkan oleh transformasi, yaitu[10]:

$$
f\left(l_{n, i} ; \beta, \alpha, \xi\right)=\left\{\begin{array}{l}
\frac{1}{\alpha}\left\{1+\xi\left(\frac{l_{n, i}-\beta}{\alpha}\right)\right\}^{-\frac{1}{\xi}-1} \exp \left\{-\left(1+\xi\left(\frac{l_{n, i}-\beta}{\alpha}\right)\right)^{-\frac{1}{\xi}}\right\} ; \xi \neq 0 \\
\frac{1}{\alpha} \exp \left\{-\left(\frac{l_{n, i}-\beta}{\alpha}\right)\right\} \exp \left\{-\exp \left(-\frac{l_{n, i}-\beta}{\alpha}\right)\right\} ; \xi=0
\end{array}\right.
$$

dimana, $1+\xi\left(\left(l_{n, i}-\beta\right) / \alpha\right)>0$; jika $\xi \neq 0$.

\section{ESTIMASI PARAMETER GEV}

Pada penelitian ini estimasi parameter dilakukan dengan maximum likelihood estimation (MLE). MLE merupakan salah satu metode estimasi yang memaksimumkan fungsi likelihood untuk mendapatkan estimasi parameternya. Fungsi likelihood dari sub-periode maksimum PDF GEV, yaitu[10]:

$$
L\left(l_{n, 1}, l_{n, 2}, \ldots, l_{n, \mathrm{~g}} \mid \beta, \alpha, \xi\right)=\prod_{i=1}^{g} f\left(l_{n, i} ; \beta, \alpha, \xi\right)
$$

Prosedur estimasi nonlinear dapat digunakan untuk menetapkan estimasi maksimum likelihood dari parameter $\beta, \alpha$, dan $\xi$. Estimasi ini tidak bias, secara asimtotis normal, dan variansi minimum di bawah asumsi layak.

\section{VALUE AT RISK DENGAN PENDEKATAN METODE BLOCK MAXIMA-GEV}

Secara umum VaR didefinisikan sebagai suatu metode yang digunakan untuk mengukur kerugian maksimum yang mungkin terjadi karena memiliki jumlah aset tertentu dalam periode tertentu sehingga dapat ditoleransi dengan tingkat kepercayaan tertentu. Pendekatan extreme value pada VaR ditentukan dengan pendekatan GEV yaitu pendekatan kuantil dengan distribusi GEV. VaR dengan pendekatan metode block maxima-GEV, yaitu[10]: 


$$
\operatorname{VaR}=\left\{\begin{array}{l}
\beta-\frac{\alpha}{\xi}\left\{1-[-n \ln (1-p)]^{-\xi}\right\} ; \xi \neq 0 \\
\beta-\alpha \ln [-n \ln (1-p)] ; \xi=0
\end{array}\right.
$$

dimana $n$ adalah panjang sub-periode atau banyaknya blok.

\section{STUDI KASUS}

Data yang digunakan dalam penelitian adalah data penutupan harga saham harian LQ45 periode 1 Januari sampai 31 Desember 2018 yang diperoleh dari http://www.finance.yahoo.com/. Dari 45 saham terdapat 37 saham yang selalu terdaftar atau konsisten masuk pada indeks LQ45 untuk periode 1 Januari sampai 31 Desember 2018. Langkah pertama yang dilakukan adalah menghitung return masing-masing saham kemudian menghitung mean return masing-masing saham.

Tabel 1 Daftar nilai mean return positif dan variansi return saham LQ45

\begin{tabular}{ccccccc}
\hline Kode & Mean Return & $\begin{array}{c}\text { Variansi } \\
\text { Return }\end{array}$ & & Kode & Mean Return & $\begin{array}{c}\text { Variansi } \\
\text { Return }\end{array}$ \\
\hline PTBA & 0,00215 & 0,00069 & & SMGR & 0,00058 & 0,00073 \\
ANTM & 0,00078 & 0,00074 & & INCO & 0,00046 & 0,00082 \\
PGAS & 0,00074 & 0,00139 & & WIKA & 0,00025 & 0,00070 \\
BBCA & 0,00066 & 0,00019 & & BRPT & 0,00022 & 0,00057 \\
ICBP & 0,00062 & 0,00025 & & BBRI & 0,00002 & 0,00046 \\
\hline
\end{tabular}

Pada Tabel 1 diketahui bahwa ada 10 saham dari 37 saham LQ45 periode 1 Januari sampai 31 Desember 2018 yang memiliki nilai mean return positif. Dari 10 saham yang memiliki nilai mean return positif, dipilih lima saham untuk pembentukan portofolio dengan kriteria yaitu saham yang memiliki nilai mean return positif tertinggi antara lain Tambang Batubara Bukit Asam Tbk (PTBA), Aneka Tambang Tbk (ANTM), Perusahaan Gas Negara Tbk (PGAS), Bank Central Asia Tbk (BBCA), dan Indofood CBP Sukses Makmur Tbk (ICBP). Nilai variansi berfungsi untuk mengukur pergerakan harga saham. Dari Tabel 1 dapat diketahui juga bahwa saham PTBA, ANTM, PGAS, BBCA, dan ICBP memiliki peluang untuk mengalami keuntungan atau kerugian yang besar, hal ini dikarenakan nilai variansi dari masing-masing lima saham tersebut cukup besar.

Tahap berikutnya menghitung return portofolio. Return portofolio yang dibentuk adalah return portofolio dengan bobot berdasarkan proporsi nilai mean return dari masing-masing saham PTBA, ANTM, PGAS, BBCA, dan ICBP. Total dari nilai mean return dari kelima saham tersebut adalah 0,00494. Sehingga bobot atau proporsi untuk saham PTBA sebesar 43,48\%, ANTM sebesar 15,74\%, PGAS sebesar 14,93\%, BBCA sebesar 13,36\%, dan ICBP sebesar 12,50\%. Statistik deskriptif untuk data return portofolio LQ45 periode 1 Januari sampai 31 Desember 2018, sebagai berikut:

Tabel 2 Statistik deskriptif data return portofolio LQ45

\begin{tabular}{cc}
\hline Karakteristik & Nilai \\
\hline Jumlah data & 260 \\
Mean & 0,00133 \\
Minimum & $-0,07197$ \\
Maksimum & 0,04620 \\
Standar deviasi & 0,01638 \\
Variansi & 0,00027 \\
Skeweness & $-0,45002$ \\
Kurtosis & 1,76922 \\
\hline
\end{tabular}


Berdasarkan Tabel 2 dapat dilihat bahwa data return portofolio LQ45 yang mana terdiri dari saham PTBA, ANTM, PGAS, BBCA, dan ICBP untuk periode 1 Januari sampai 31 Desember 2018 berjumlah 260 hari dengan mean atau rata-rata return portofolio sebesar 0,00133 . Nilai maksimum return portofolio sebesar 0,04620, sedangkan nilai minimumnya adalah -0,07197.

Nilai skewness atau nilai kemiringan dari data return portofolio LQ45 adalah -0,45002 (dapat dilihat pada Tabel 2), itu artinya nilai skewness < 0, sehingga dapat disimpulkan bahwa data return portofolio LQ45 untuk periode 1 Januari sampai 31 Desember 2018 memiliki kurva yang condong ke kiri, hal ini dikarenakan nilai skewness < 0 . Selain itu, nilai kurtosis atau nilai keruncingan dari data return portofolio LQ45 adalah 1,76922 (dapat dilihat pada Tabel 2), hal ini menunjukkan bahwa data return portofolio LQ45 memiliki kurva platikurtik, hal ini dikarenakan nilai kurtosis-nya $<3$.

Tahap selanjutnya adalah menguji adanya kondisi GEV pada data return portofolio LQ45. Ditentukan jumlah blok dari data yang digunakan dalam penulisan ini, yaitu dari 260 return portofolio, blok dibentuk berdasarkan mingguan, yang mana setiap satu minggunya terdapat lima hari kerja, sehingga ada 52 blok $(\mathrm{n}=52)$. Untuk menguji apakah data return portofolio LQ45 yang digunakan mengikuti distribusi GEV, maka digunakan uji kesesuaian distribusi. Uji kesesuaian distribusi ini menggunakan uji Kolmogorov-Smirnov, dimana distribusi teoritik yang diharapkan adalah distribusi GEV dan tingkat kesalahan (alpha) yang digunakan adalah 5\%, dengan hipotesis sebagai berikut:

$H_{0}$ : Data return portofolio berdistribusi GEV

$H_{1}$ : Data return portofolio tidak berdistribusi GEV

Berdasarkan hasil pengujian Kolmogorov-Smirnov dengan menggunakan software EasyFit, dapat diketahui bahwa return portofolio LQ45 periode 1 Januari sampai 31 Desember 2018 yang dibentuk dari saham PTBA, ANTM, PGAS, BBCA, dan ICBP menghasilkan nilai p-value sebesar 0,12019, yang mana nilai $p$-value tersebut lebih dari nilai alpha atau tingkat kesalahan yang digunakan yaitu $0,12019>5 \%$. Sehingga diperoleh keputusan gagal tolak $H_{0}$ atau dengan kata lain $H_{0}$ diterima, yang artinya bahwa data return portofolio LQ45 mengikuti distribusi GEV.

Data return portofolio LQ45 memenuhi kondisi terdapat GEV, sehingga dilanjutkan dengan tahap mengestimasi parameter GEV. Terdapat tiga parameter GEV yang diestimasi yaitu parameter lokasi (location) yang disimbolkan dengan $\beta$, parameter skala (scale) yang disimbolkan dengan $\alpha$, dan parameter bentuk (shape) yang disimbolkan dengan $\xi$. Berikut hasil estimasi parameter GEV, yaitu

Tabel 3 Hasil estimasi parameter GEV data return portofolio LQ45

\begin{tabular}{cc}
\hline Parameter & Return Portofolio \\
\hline Bentuk $(\xi)$ & $-0,64027$ \\
Lokasi $(\beta)$ & 0,03586 \\
Skala $(\alpha)$ & 0,00755 \\
\hline
\end{tabular}

Pada Tabel 3 dapat diketahui bahwa hasil estimasi parameter GEV menunjukkan bahwa parameter bentuk untuk data return portofolio pada indeks LQ45 periode 1 Januari sampai 31 Desember 2018 sebesar -0,64027. Dari nilai parameter bentuk ini, dapat diketahui bahwa data return portofolio LQ45 memiliki short tailed (ekor pendek), hal ini dikarenakan nilai parameter bentuk < 0 . Selain itu juga, dari nilai parameter bentuk menentukan perilaku ekor, dimana diketahui bahwa nilai parameter bentuk $(\xi)$ kurang dari $0(-0,64027<0)$ yang artinya data return portofolio pada indeks LQ45 termasuk tipe III (distribusi Weibull).

Estimasi parameter lokasi yang dihasilkan menyatakan letak titik pemusatan data, dimana dari Tabel 3 parameter lokasi dari data return portofolio LQ45 untuk periode 1 Januari sampai 31 Desember 2018 sebesar $\beta=0,03586$. Estimasi parameter skala menjelaskan tentang keragaman data, dimana dari Tabel 3 diketahui bahwa hasil estimasi parameter skala adalah sebesar $\alpha=0,00755$. 


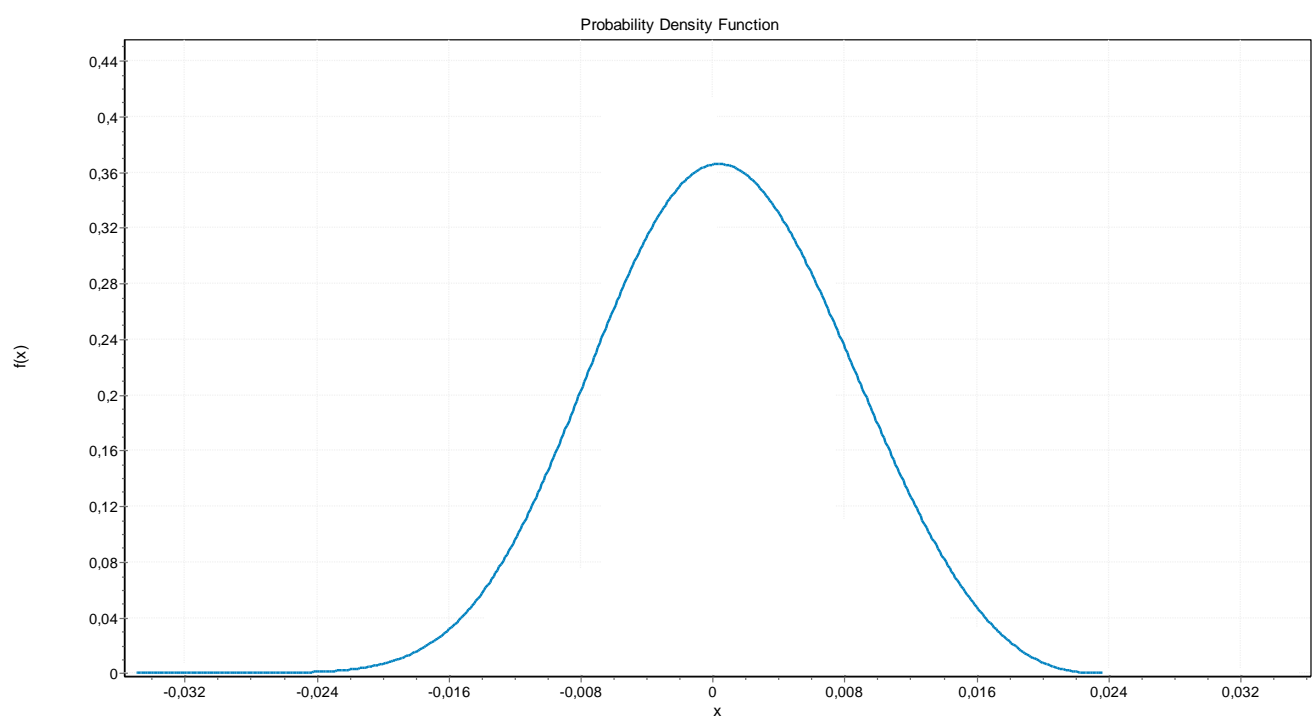

Gambar 1 Kurva data return portofolio LQ45

Kurva data return portofolio LQ45 periode 1 Januari sampai 31 Desember 2018 yang berdistribusi GEV ditunjukkan pada Gambar 1. Tahap terakhir dalam analisis data adalah melakukan analisis risiko portofolio LQ45 menggunakan VaR dengan pendekatan metode block maxima-GEV. Hasil perhitungan VaR untuk data return portofolio LQ45, yaitu:

Tabel 4 Hasil VaR pada data return portofolio LQ45

\begin{tabular}{cc}
\hline & Nilai \\
\hline Tingkat Kepercayaan & $95 \%$ \\
Jumlah Blok & 52 \\
VaR & 0,02555 \\
\hline
\end{tabular}

Berdasarkan Tabel 4, diketahui bahwa dengan tingkat kepercayaan sebesar 95\% dan jumlah blok sebanyak 52 blok, maka didapatkan nilai VaR untuk dari return portofolio LQ45 yang terdiri dari saham PTBA, ANTM, PGAS, BBCA, dan ICBP adalah sebesar 0,02555. Hal ini berarti, risiko maksimal yang diperoleh dengan pendekatan GEV yang mungkin dihadapi oleh investor ketika berinvestasi portofolio pada indeks LQ45 adalah sebesar 2,555\% dari total nilai investasinya.

\section{KESIMPULAN}

Berdasarkan hasil analisis yang telah dilakukan, dapat diambil kesimpulan bahwa analisis yang dilakukan pada portofolio LQ45 untuk periode 1 Januari sampai 31 Desember 2018 menggunakan VaR dengan pendekatan metode block maxima-GEV menghasilkan nilai VaR dengan tingkat kesalahan 5\% adalah sebesar 0,02555 atau 2,555\% dari total nilai investasinya, artinya jika investor berinvestasi sebesar Rp100.000.000,00,- maka investor tersebut mempunyai risiko maksimum yang mungkin dihadapinya sebesar Rp2.555.000,00.

\section{DAFTAR PUSTAKA}

[1] Ambarsari A, Sudarno, Tarno. Perbandingan Pendekatan Generalized Extreme Value dan Generalized Pareto Distribution untuk Perhitungan Value at Risk pada Portofolio Saham. Jurnal Gaussian. 2016; 5(3):361-371.

[2] Fauziyah NA. Analisis Risiko pada Portofolio Syariah dengan Pemodelan Value at Risk (VaR) Block Maxima-Generalized Extreme Value. Jurnal Konvergensi. 2014; 4(1):5360 . 
[3] Ghozali I. Manajemen Risiko Perbankan Pendekatan Kuantitatif Value at Risk (VaR). Semarang: Badan Penerbit Universitas Diponegoro; 2007.

[4] Kotz S, Nadarajah S. Extreme Value Distribution Theory and Applications. London: Imperia Colloge Press; 2000.

[5] Gilli M, Kellezi E. An Application of Extreme Value Theory for Measuring Financial Risk. Computational Economics. 2006; 27(1):1-23.

[6] Tandelilin E. Portofolio dan Investasi Teori dan Aplikasi. Yogyakarta: Kanisisus; 2010.

[7] Jorion P. Value at Risk The New Benchmark for Managing Financial Risk. New York: The McGaw-Hill Companies Inc; 2002.

[8] Rohmah SM, Suharsono A. Estimasi Value at Risk dalam Investasi Saham Subsektor Perbankan di Bursa Efek Indonesia dengan Pendekatan Extreme Value Theory. Jurnal Sains dan Seni. 2017; 6(2):205-211.

[9] Dharmawan K. Estimasi Nilai VaR Dinamis Indeks Saham Menggunakan Peaks-Over Threshold dan Block Maxima. Jurnal Matematika. 2012; 2(2):1-12.

[10] Tsay RS. Analysis of Financial Time Series. Chicago: A John Wiley \& Son, Inc; 2010.

\author{
NANDA AYUNI : Jurusan Matematika FMIPA UNTAN, Pontianak \\ nandayunii17@gmail.com \\ SETYO WIRA RIZKI : Jurusan Matematika FMIPA UNTAN, Pontianak \\ setyo.wirarizki@math.untan.ac.id \\ HENDRA PERDANA : Jurusan Matematika FMIPA UNTAN, Pontianak \\ hendra.perdana@math.untan.ac.id
}

